\title{
The efficacy and safety of lanreotide Autogel in patients with acromegaly previously treated with octreotide LAR
}

\author{
S G Ashwell, J S Bevan ${ }^{1}$, O M Edwards ${ }^{2}$, M M Harris ${ }^{3}$, C Holmes ${ }^{3}$, M A Middleton ${ }^{1}$ and R A James ${ }^{3}$ \\ School of Clinical Medical Sciences, University of Newcastle upon Tyne, UK, ${ }^{1}$ Department of Endocrinology, Aberdeen Royal Infirmary, Aberdeen, UK, \\ ${ }^{2}$ Department of Medicine and Endocrinology, Addenbrookes Hospital, Cambridge, UK and ${ }^{3}$ Department of Endocrinology, Royal Victoria Infirmary, \\ Newcastle upon Tyne, UK \\ (Correspondence should be addressed to S G Ashwell; Wellcome Laboratories, Royal Victoria Infirmary, Queen Victoria Road, Newcastle upon Tyne, \\ NE1 4LP; Email: s.g.ashwell@ncl.ac.uk)
}

\begin{abstract}
Objective: Lanreotide Autogel is a sustained-release aqueous gel formulation supplied in a prefilled syringe, with injection volume $<0.5 \mathrm{ml}$. The aim of this study was to establish the efficacy and safety of Autogel in patients with acromegaly previously treated with octreotide LAR.

Design: A 28-week, open, multicentre study.

Patients: Twelve patients with acromegaly, treated with $20 \mathrm{mg}$ octreotide LAR for $>4$ months, with serum GH levels $<10.0 \mathrm{mU} / \mathrm{l}$.

Methods: Autogel $(90 \mathrm{mg})$ was given every 28 days during weeks $0-12$. At week 16 the dose was titrated based on GH levels at weeks 8 and 12. If GH levels were $<2.0,2.0-5.0$, or $>5.0 \mathrm{mU} / \mathrm{l}$, Autogel was reduced to $60 \mathrm{mg}$, maintained at $90 \mathrm{mg}$, or increased to $120 \mathrm{mg}$ respectively, for the next three injections. GH and IGF-I levels were reassessed at weeks 24 and 28.

Results: Ten patients completed the study. Five remained on $90 \mathrm{mg}$ Autogel throughout the study; in two patients the dose was reduced to $60 \mathrm{mg}$ from week 16; in three patients it was increased to $120 \mathrm{mg}$. Mean GH levels were: baseline, $3.0 \pm 1.7 \mathrm{mU} / \mathrm{l}$; week $12,3.5 \pm 1.8 \mathrm{mU} / \mathrm{l}$; week 28 , $3.3 \pm 1.6 \mathrm{mU} / \mathrm{l}(\mathrm{NS})$. Mean IGF-I levels were: baseline, $212 \pm 70 \mu \mathrm{g} / \mathrm{l}$; week $12,185 \pm 91 \mu \mathrm{g} / \mathrm{l}$; week 28: $154 \pm 61 \mu \mathrm{g} / \mathrm{l}(P=0.027)$. Six patients at baseline and eight at week 28 had normalised GH and IGF-I levels. Three patients reported adverse events: musculoskeletal pain $(n=2)$ and injection-site symptoms $(n=1)$.

Conclusions: Lanreotide Autogel is effective and well tolerated in patients with acromegaly. This study in a small group of patients with well-controlled acromegaly suggests that the majority of patients switched from $20 \mathrm{mg}$ LAR to $90 \mathrm{mg}$ Autogel will have equivalent or better disease control.
\end{abstract}

European Journal of Endocrinology 150 473-480

\section{Introduction}

The introduction of long-acting somatostatin analogues has transformed the treatment of acromegaly, enabling effective symptom and disease control for patients in whom surgery and/or radiotherapy have not effected a cure. Slow-release preparations have further improved control and efficacy (1) and these agents are now the medical therapy of choice in this situation $(2,3)$. Somatostatin analogues also provide effective primary medical therapy for a proportion of patients with de-novo acromegaly, in whom there results normalisation of GH and IGF-I levels, together with substantial tumour shrinkage $(4,5)$.

Native somatostatin-14 has a plasma half-life of only approximately $2.5 \mathrm{~min}(6,7)$. The synthetic somatostatin analogues, lanreotide and octreotide, have longer plasma half-lives of 90 and $110 \mathrm{~min}$ respectively $(8,9)$. However, multiple daily injections or continuous subcutaneous infusion of these drugs remains a necessity and this detracts from patient acceptability.

Depot formulations of these peptides, octreotide LAR (LAR) and lanreotide LA, have been developed by incorporation of the somatostatin analogue into a biodegradable polylactide-polyglycolide co-polymer. These preparations result in extended drug release following intramuscular injection and provide effective plasma drug levels and growth hormone suppression for approximately 28 and 14 days following a single intramuscular injection of octreotide LAR and lanreotide LA respectively $(1,10,11)$.

Recently, a new formulation of lanreotide has become available, Autogel. This is a viscous aqueous gel, composed solely of water and lanreotide. Intramuscular injection results in a pharmacokinetic profile very close to first-order kinetics, with plasma lanreotide concentrations being maintained above the therapeutic level of $1 \mu \mathrm{g} / \mathrm{l}$ for at least 28 days after injection 
(Beaufour Ipsen, Paris, France, unpublished observations). However the pharmacokinetics of Autogel are not different if given by intramuscular or deep subcutaneous injection (Ipsen Limited, unpublished observations). Autogel is presented in a sterile, prefilled syringe in doses of 60,90 and $120 \mathrm{mg}$, with an injection volume of $0.2-0.4 \mathrm{ml}$. Elimination of the need for reconstitution with vehicle increases the ease of use of the drug and minimises wastage compared with microparticle preparations. Deep subcutaneous administration may also lead to increased treatment acceptance compared with intramuscular depot preparations.

Biochemical control of acromegaly has been reported to be equivalent with Autogel and lanreotide LA. In a study of 107 patients previously treated with $30 \mathrm{mg}$ lanreotide LA every 14, 10 or 7 days, Autogel was commenced at doses of 60,90 or $120 \mathrm{mg}$ respectively, every 28 days (12). After three injections of Autogel, disease control (as assessed by plasma lanreotide, growth hormone (GH), insulin-like growth factor-I (IGF-I) levels and symptoms) was not different to that achieved with lanreotide LA. The relative efficacy of lanreotide Autogel and octreotide LAR, and the effect of switching from LAR to Autogel have not yet been investigated.

The aims of this study were to establish the efficacy and safety of lanreotide Autogel in patients with acromegaly previously treated with octreotide LAR, to investigate whether switching from LAR to Autogel would have any impact on biochemical or symptomatic disease control, and to establish clinically equivalent doses.

\section{Subjects and methods}

This was a phase 3, open-label, multicentre study performed at three specialist UK centres, in patients with acromegaly stably treated with $20 \mathrm{mg}$ octreotide LAR. Treatment was switched to lanreotide Autogel at week 0 and disease control with Autogel therapy was compared with the patients' baseline control on LAR.

An independent ethics committee approved the study protocol and documentation at each site. The study was performed in accordance with the Declaration of Helsinki and the principles of Good Clinical and Laboratory Practices (GCP, GLP). All patients gave written informed consent before entering the study.

\section{Patients}

For inclusion, patients (aged over 18 years) with acromegaly were required to have been treated with $20 \mathrm{mg}$ LAR for at least 4 months. Mean baseline serum GH level on octreotide LAR had to be $\leq 10.0 \mathrm{mU} / \mathrm{l}$. Patients were excluded if they had undergone pituitary surgery within 6 months or radiotherapy within 1 year of the start of the study, or if either of these interventions were thought to be required during the 28-week study period. Patients were excluded if they were being treated with a dopamine agonist or a somatostatin analogue other than octreotide LAR $(20 \mathrm{mg})$. Female patients of childbearing age were excluded if they were pregnant, lactating, or were not taking adequate contraception.

Twelve patients were recruited. Two patients withdrew before week 12, one due to symptoms that may have been related to $\mathrm{GH}$ control (see adverse events), and one due to recurrent depression, thought to be unrelated to Autogel treatment. Ten patients completed the study and represent the per-protocol population (Tables 1 and 2). All results reflect data collected from this population. This was a group of patients with well-controlled acromegaly (baseline serum GH $3.0 \pm 1.7 \mathrm{mU} / \mathrm{l}$; $\quad$ IGF-I $212 \pm 70.1 \mu \mathrm{g} / \mathrm{l})$. However, requirement for somatostatin analogue therapy was demonstrated by mean serum GH and IGF-I levels of $8.0 \pm 3.7 \mathrm{mU} / \mathrm{l}$ and $453 \pm 145 \mu \mathrm{g} / \mathrm{l}$ respectively, following withdrawal from, or prior to commencement of therapy, at a mean of $44 \pm 23$ months before the study.

\section{Study design}

Patient eligibility was confirmed by a screening visit 4 weeks before the study commenced at week 0 . This included an assessment of mean serum GH and IGF-I levels. The study was then conducted in two stages (Fig. 1).

Stage 1 (weeks 0-12) Baseline serum GH and IGF-I levels were measured at week 0, 28 days after the final injection of octreotide LAR. Patients were given $90 \mathrm{mg}$ Autogel, by deep subcutaneous injection. This injection was repeated at weeks 4,8 and 12. Serum GH, IGF-I and lanreotide measurements were repeated before Autogel injection at weeks 8 and 12 .

Stage 2 (weeks 16-28) The dose of Autogel was titrated at week 16 based on serum GH concentrations obtained at weeks 8 and 12 . If at both of these assessments mean serum GH level was <2.0, 2.0-5.0 or

Table 1 Patient characteristics (per protocol population).

\begin{tabular}{lcc}
\hline & Value & Range \\
\hline Number of patients $(n)$ & 10 & - \\
Age (years) (mean \pm S.D.) & $55.8 \pm 9.1$ & $41.8-72.8$ \\
Gender (male:female) & $6: 4$ & \\
$\begin{array}{l}\text { Duration of previous LAR treatment } \\
\text { (months) (mean } \pm \text { S.D.) }\end{array}$ & $32.8 \pm 15.7$ & $9-55$ \\
Previous pituitary surgery $(n)$ & & \\
Previous pituitary radiotherapy $(n)$ & 5 & \\
Baseline GH (mU/I) (mean \pm S.D.) & $3.0 \pm 1.7$ & $0.5-5.8$ \\
Baseline IGF-I ( $\mu$ g/l) (mean \pm S.D.) & $212 \pm 70.1$ & $108-336$ \\
Mean GH off somatostatin analogue & $8.0 \pm 3.7$ & $2.0-16.4$ \\
$\quad$ therapy (mU/I) (mean \pm S.D.) & & \\
Mean IGF-I off somatostatin analogue & $485 \pm 105$ & $354-625$ \\
$\quad$ therapy ( $\mu$ g/l) (mean \pm S.D.) & & \\
\hline
\end{tabular}


Table 2 Baseline characteristics of individual patients, including details of previous treatment and GH/IGF-I levels before, or during a break from, somatostatin analogue therapy.

\begin{tabular}{|c|c|c|c|c|c|c|}
\hline $\begin{array}{l}\text { Centre and } \\
\text { Patient no. }\end{array}$ & $\begin{array}{c}\text { Surgery } \\
\text { (year) }\end{array}$ & $\begin{array}{c}\text { Radiotherapy } \\
\text { (year) }\end{array}$ & $\begin{array}{c}\text { Primary } \\
\text { pharmacotherapy } \\
\text { (year) }\end{array}$ & $\begin{array}{c}\text { Mean GH concentration } \\
\text { off somatostatin } \\
\text { analogue therapy } \\
(\mathrm{mU} / \mathrm{l})\end{array}$ & $\begin{array}{c}\text { IGF-I concentration off } \\
\text { somatostatin analogue } \\
\text { therapy }(\mu \mathrm{g} / \mathrm{l})\end{array}$ & $\begin{array}{l}\text { Interval between } \\
\text { initial GH/IGF-I } \\
\text { assessment and } \\
\text { study start (months) }\end{array}$ \\
\hline 1.001 & 1996 & No & No & 7.2 & 603 & 31 \\
\hline 1.002 & No & 1989 & No & 8.7 & 465 & 52 \\
\hline 1.003 & 1995 & No & No & 6.2 & 435 & 44 \\
\hline 1.004 & 1994 & No & No & 6.4 & 366 & 46 \\
\hline 1.005 & No & No & Octreotide LAR '97 & 9.8 & 618 & 47 \\
\hline 2.003 & 1998 \& 1999 & 1999 & No & 6.5 & 549 & 14 \\
\hline 2.004 & No & 2000 & No & 8.7 & 404 & 9 \\
\hline 3.001 & 1992 & 1992 & No & 7.8 & 432 & 77 \\
\hline 3.002 & 1995 & 1995 & No & 16.4 & 625 & 81 \\
\hline 3.003 & 1997 & No & No & 2.0 & 353 & 34 \\
\hline Mean & & & & $8.0 \pm 3.7$ & $485 \pm 105$ & $43.5 \pm 23.4$ \\
\hline
\end{tabular}

$>5.0 \mathrm{mU} / \mathrm{l}$, the Autogel dose was reduced to $60 \mathrm{mg}$, maintained at $90 \mathrm{mg}$ or increased to $120 \mathrm{mg}$ every 28 days respectively. Serum IGF-I values were not used to guide the dose titration. This adjusted dose was given at week 16 and repeated at weeks 20 and 24. Mean serum GH, IGF-I and lanreotide measurements were repeated at weeks 24 and 28 .

\section{Treatment}

Lanreotide Autogel was supplied in prefilled syringes with injection volumes of $0.2,0.3$ and $0.4 \mathrm{ml}$ for the 60,90 and $120 \mathrm{mg}$ doses respectively. The syringes are fitted with a $2 \mathrm{~cm}$ needle of external diameter $1.2 \mathrm{~mm}(1.4 \mathrm{~mm}$ for the $120 \mathrm{mg}$ dose). All injections were given in the upper external quadrant of the buttock, perpendicular to, and without pinching the skin, and the needle was inserted to its full length. The syringes were stored in a refrigerator until use, but were brought to room temperature at least 30 min before injection.

\section{Sampling procedures and hormone assays}

Blood was collected at each specified time point of the biochemical assessment into tubes containing clot activator. Each sample was allowed to coagulate and was then centrifuged at 3000 r.p.m. for 15 min. The supernatant was transferred into two separate plain tubes for analysis of GH and IGF-I concentrations. The samples were then stored at $-20^{\circ} \mathrm{C}$ until the assays were performed. The remaining serum was frozen at $-20^{\circ} \mathrm{C}$ for later determination of lanreotide levels.

Prior to each GH/IGF-I assessment patients were asked to fast from $2200 \mathrm{~h}$ the previous day, but were allowed a light breakfast after the first blood sample had been taken. Nine blood samples were taken at 30min intervals for $4 \mathrm{~h}$ and the mean GH level determined from these. IGF-I concentration was determined from the first fasting sample.

GH was measured using the Immulite ${ }^{\circledR}$ method (EURO/DPC Ltd, Glyn Rhonwy, Llanberis, UK). This is an automated, solid-phase, two-site chemiluminescent,

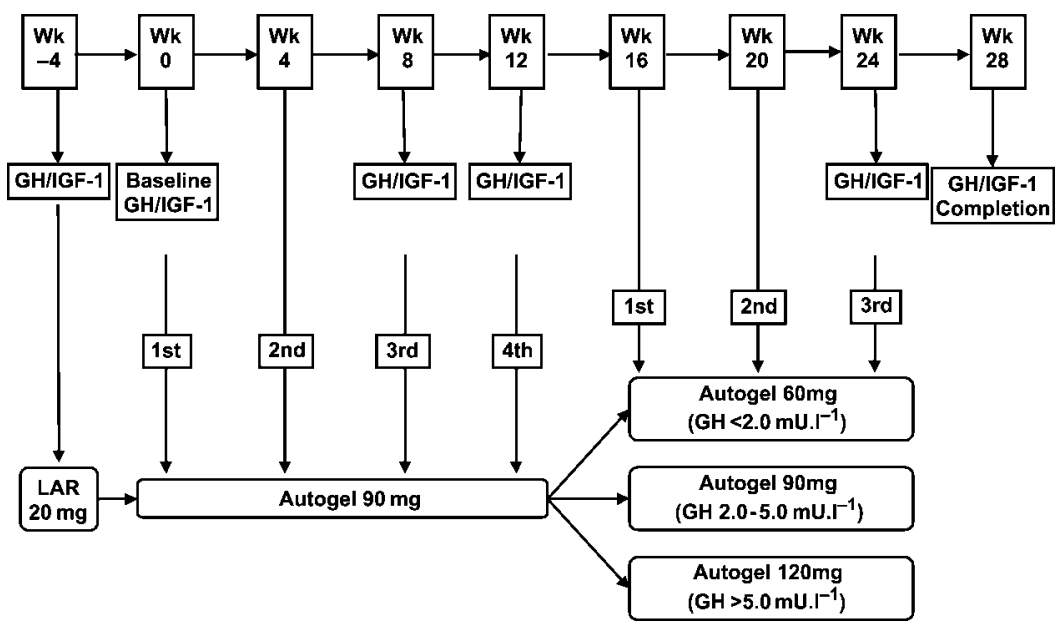

Figure 1 Schematic representation of study design. After a screening visit (week -4), patients received $90 \mathrm{mg}$ Autogel every 28 days from weeks 0 to 12. Based on mean $\mathrm{GH}$ levels at weeks 8 and 12, the Autogel dose was adjusted up to $120 \mathrm{mg}$, down to $60 \mathrm{mg}$, or maintained at $90 \mathrm{mg}$. This dose was given at weeks 16,20 and 24. GH and IGF-I measurements were repeated at weeks 24 and 28. 
immunometric assay. It has a detection range of $0.13-$ $104 \mathrm{mU} / \mathrm{l}$ and a sensitivity of $0.008 \mathrm{mU} / \mathrm{ml}$. The data sheet reports an intra-assay coefficient of variation (CV) of 5.3-6.5\% and an inter-assay CV of 5.5-6.2\%.

IGF-I levels were determined using an immunoradiometric assay (IMRA) (Nicolas Institute Diagnostics, Nimegen, The Netherlands). It has a detection range of $80-3000 \mu \mathrm{g} / \mathrm{l}$ and sensitivity of $6 \mu \mathrm{g} / \mathrm{l}$. The reference range for men and women aged 40-54 years is $75-306 \mu \mathrm{g} / \mathrm{l}$ and in those aged 55 years or over, $48-225 \mu \mathrm{g} / \mathrm{l}$. The data sheet reports an intra-assay CV of 3.3-4.6\% and an inter-assay CV of 9.3-15.8\%. Both assays were performed by a central laboratory (Chandos Clinical Research, London, UK).

Lanreotide levels were measured using a validated Ipsen RIA and were performed at Ipsen Pharma central laboratory (Pharmacokinetic Service, Barcelona, Spain). This assay has a lower detection limit of $0.08 \mu \mathrm{g} / \mathrm{l}$. The intra-assay CV was $5 \%$ and the interassay $\mathrm{CV}$ was $<13 \%$.

\section{Data analysis}

Paired comparisons of GH and IGF-I levels at week 28 and those at baseline were made using a paired $t$-test. Comparisons of the relative proportions of patients achieving normalised GH and IGF-I levels were made using Fisher's exact test.

\section{Results}

\section{Efficacy of Ianreotide AutogeI}

Mean serum GH level for the whole group at baseline, 28 days after the final injection of LAR, was 3.0 $\pm 1.7 \mathrm{mU} / \mathrm{l}$ (mean \pm S.D.). This increased to $3.9 \pm 1.9 \mathrm{mU} / \mathrm{l}$ at week 8 , but declined to $3.5 \pm 1.8 \mathrm{mU} / \mathrm{l}$ by week 12 . By week 28 , the group's mean serum GH level declined to levels similar to baseline: $3.3 \pm 1.6 \mathrm{mU} / \mathrm{l}$ (Fig. 2, Table 3). There were no statistically significant differences in mean GH levels from baseline at any time point. Individual patients' mean GH levels are shown in Fig. 3.

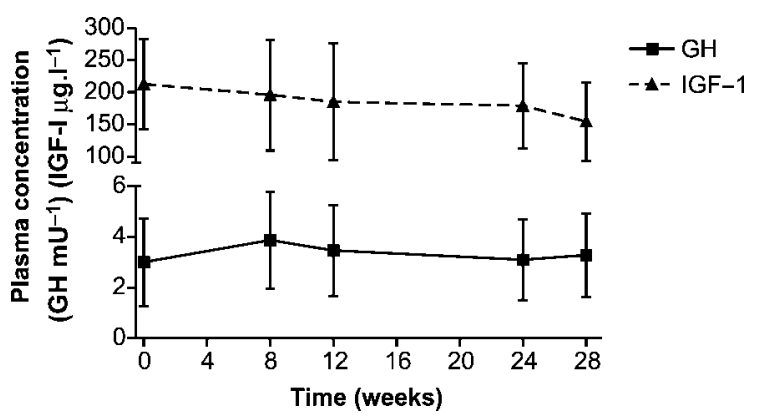

Figure 2 Mean serum levels of GH (mU/I) ( $\mathbf{n})$ and IGF-I $(\mu \mathrm{g} / \mathrm{l})(\mathbf{\Delta})$ (mean \pm S.D.) for the per protocol population $(n=10)$ treated with lanreotide Autogel. There were no statistically significant differences in mean $\mathrm{GH}$ levels at any time point from baseline. Mean IGF-I levels were lower at week 28 than at baseline $(P=0.027)$.
Mean serum IGF-I concentration at baseline was $212 \pm 70 \mu \mathrm{g} / \mathrm{l}$. From week 0 to week 28 this progressively declined for the group, evident at all time points. Mean serum IGF-I concentration at the study endpoint (week 28) was statistically significantly lower than that at baseline: $154 \pm 61$ vs $212 \pm 70 \mu \mathrm{g} / \mathrm{l}(P=0.027)$. Individual patients' IGF-I levels are shown in Fig. 4.

At baseline, nine patients had mean serum GH concentrations $<5.0 \mathrm{mU} / \mathrm{l}$ and seven patients had a normalised age-adjusted IGF-I concentration. Nine patients fulfilled each of these criteria at the study endpoint. At baseline, $60 \%$ of patients had both a mean serum GH level $<5.0 \mathrm{mUl}^{-1}$ and a normalised ageadjusted IGF-I level. This proportion rose to $80 \%$ at the study endpoint $(P=0.003)$.

\section{Lanreotide levels}

Trough serum lanreotide levels rose gradually from $1.9 \pm 0.5 \mu \mathrm{g} / \mathrm{l}$ at week 8 to $3.3 \pm 1.0 \mu \mathrm{g} / \mathrm{l}$ at study endpoint (Table 3 ). A steady state in lanreotide levels was not reached by week 28 for the group as a whole.

\section{Lanreotide Autogel dose titration}

When the Autogel dose was titrated at week 16, the largest number of patients (five out of ten) had achieved GH levels within the target range and thus remained on $90 \mathrm{mg}$ Autogel every 28 days. In two patients, the dose was reduced to $60 \mathrm{mg}$ due to mean serum $\mathrm{GH}$ levels $<2.0 \mathrm{mU} / \mathrm{l}$, and in three patients an increase to $120 \mathrm{mg}$ Autogel was required in order to achieve optimal GH control.

GH, IGF-I and lanreotide levels were analysed separately according to the Autogel dose after titration, in the second stage of the study (Table 4, Fig. 5). Serum lanreotide levels changed little between week 12 and study endpoint in patients in whom the dose of Autogel was reduced to $60 \mathrm{mg}$. These patients $(n=2)$ had very low mean baseline GH levels that showed little change throughout the observation period. In the group who remained on $90 \mathrm{mg}$ Autogel $(n=5)$, serum lanreotide levels rose between weeks 12 and 28 (2.3 \pm 0.7 and $3.1 \pm 0.9 \mu \mathrm{g} / \mathrm{l}$ respectively) and a steady state was not achieved. However, the change between weeks 24 and 28 was small $(0.4 \mu \mathrm{g} / \mathrm{l})$. Mean serum GH levels in this group also showed little change during the course of the study. In the group in whom the Autogel dose was increased to $120 \mathrm{mg}$ at week 16 , mean serum lanreotide levels more than doubled between week 12 and week 28. The early rise in serum GH levels was the most pronounced in this group, but mean GH levels were similar to baseline by week 28. Serum IGF-I levels reduced progressively in all groups.

\section{Adverse events}

Two patients withdrew from the study before week 12, one due to symptoms possibly relating to $\mathrm{GH}$ control. 
Table 3 Serum GH, IGF-I and lanreotide levels (mean \pm S.D.) for the per protocol population $(n=10)$ during the course of the study.

\begin{tabular}{|c|c|c|c|c|c|c|}
\hline $\begin{array}{l}\text { Week } \\
\text { no. }\end{array}$ & $\underset{(\mathrm{mU} / \mathrm{l})}{\mathbf{G H}}$ & $\begin{array}{c}\text { Number of patients } \\
\text { with GH } \\
<5.0 \mathrm{mU} / \mathrm{I}(n)\end{array}$ & $\begin{array}{l}\text { IGF-I } \\
(\mu g / I)\end{array}$ & $\begin{array}{l}\text { Number of patients } \\
\text { with normalised } \\
\text { age-adjusted } \\
\text { IGF-I }(n)\end{array}$ & $\begin{array}{l}\text { Number of patients } \\
\text { with normalised } \\
\text { age-adjusted IGF-I and GH } \\
<5.0 \mathrm{mU} / \mathrm{I}(n)\end{array}$ & $\begin{array}{c}\text { Trough lanreotide } \\
\qquad(\mu \mathrm{g} / \mathrm{l})\end{array}$ \\
\hline 0 & $3.0 \pm 1.7$ & 9 & $212 \pm 70$ & 7 & 6 & Not detectable \\
\hline 8 & $3.9 \pm 1.9$ & 7 & $196 \pm 86$ & 8 & 6 & $1.9 \pm 0.5$ \\
\hline 12 & $3.5 \pm 1.8$ & 7 & $185 \pm 91$ & 8 & 6 & $2.3 \pm 0.7$ \\
\hline 24 & $3.1 \pm 1.6$ & 9 & $179 \pm 66$ & 9 & 8 & $2.8 \pm 1.0$ \\
\hline 28 & $3.3 \pm 1.6$ & 9 & $154 \pm 61^{*}$ & 9 & 8 & $3.3 \pm 1.0$ \\
\hline
\end{tabular}

${ }^{*} P=0.027$ for comparison of mean IGF-I level at week 28 and week 0 (paired $t$-test).
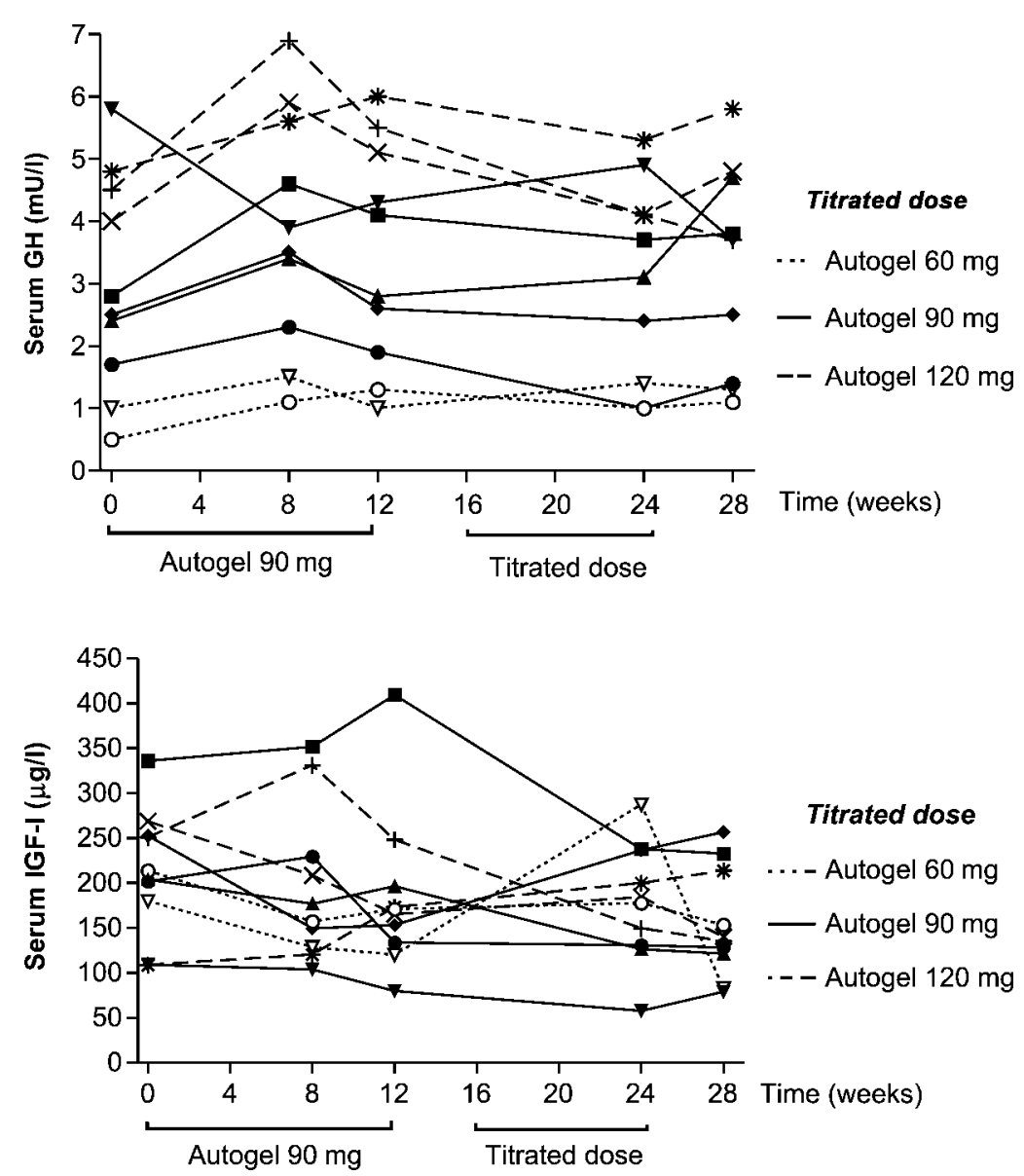

Figure 3 Mean serum GH levels in individual patients $(n=10)$ treated with lanreotide Autogel. Based on GH levels at weeks 8 and 12 . the treatment dose was adjusted from week 16 up to $120 \mathrm{mg}(---)$, down to $60 \mathrm{mg}(\cdots)$, or maintained at $90 \mathrm{mg} \mathrm{(-)}$.

Table 4 Subgroup analysis of serum GH, IGF-I and lanreotide levels (mean \pm S.D.) in the per protocol population $(n=10)$ according to the titrated dose of Autogel at week 16.

\begin{tabular}{lccccc}
\hline Dose & No. of patients & Week no. & GH $(\mathrm{mU} / \mathrm{l})$ & IGF-I $(\mu \mathrm{g} / \mathrm{l})$ & Lanreotide $(\mu \mathrm{g} / \mathrm{l})$ \\
\hline $60 \mathrm{mg}$ & 2 & 0 & 0.8 & 197 & Not detectable \\
& & 12 & 1.2 & 145 & 2.3 \\
$90 \mathrm{~g}$ & 5 & 0 & 1.2 & 118 & 2.3 \\
& & 12 & $3.0 \pm 1.6$ & $221 \pm 83$ & Not detectable \\
$120 \mathrm{mg}$ & & 28 & $3.1 \pm 1.0$ & $194 \pm 127$ & $2.3 \pm 0.7$ \\
& \multirow{3}{*}{} & 0 & $4.2 \pm 1.3$ & $164 \pm 77$ & $3.1 \pm 0.9$ \\
& & 12 & $5.4 \pm 0.4$ & $209 \pm 88$ & Not detectable \\
& & 28 & $4.8 \pm 1.1$ & $195 \pm 46$ & $2.1 \pm 1.0$ \\
\hline
\end{tabular}




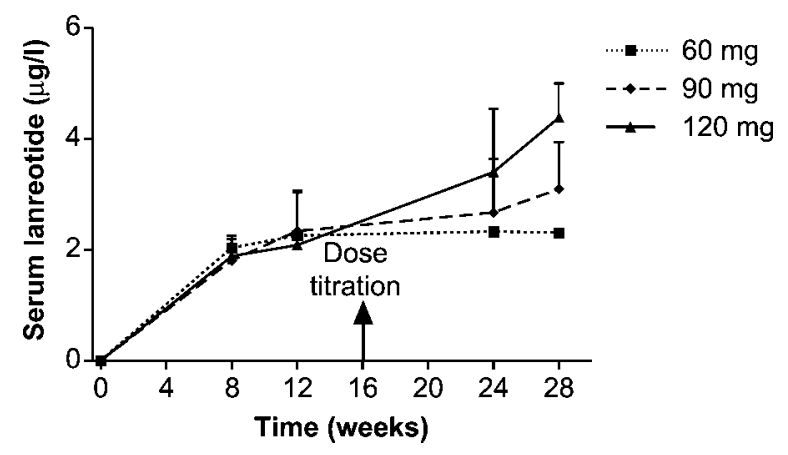

Figure 5 Serum lanreotide levels in patients treated with $90 \mathrm{mg}$ lanreotide Autogel from weeks 0 to 12 and either $60(\mathbf{\bullet}), 90(\bullet)$ or 120 ( 1$) \mathrm{mg}$ in weeks 16-24. The Autogel dose was titrated at week 16 based on GH levels assessed at weeks 8 and 12. Data points represent means \pm S.D.: $90 \mathrm{mg}(n=5), 120 \mathrm{mg}(n=3)$, $60 \mathrm{mg}(n=2$, mean alone shown).

This patient complained of headaches from week 2, sweating and snoring from week 4 , and digital enlargement from week 6 , which led to his withdrawal at week 12. Mean serum GH levels at screening, and at weeks 0 , 8 and 12 were $6.1,4.7,6.3$ and $7.8 \mathrm{mU} / \mathrm{l}$ respectively, although the data for week 12 were not available at the time of withdrawal. Four other patients reported adverse events: respiratory arrest during hip replacement surgery, considered to be unrelated to the Autogel treatment $(n=1)$; pain and swelling at the site of Autogel injection $(n=1)$; joint pain $(n=1)$; and intermittent back pain $(n=1)$. These events were all classified as mild to moderate. No gastrointestinal adverse events were reported.

\section{Discussion}

The efficacy of lanreotide Autogel in patients with acromegaly has previously been compared only with that of its microparticle formulation, lanreotide LA $(12,13)$. In the first of these two sequential studies a fixed dose of Autogel was given, the starting dose being derived from the prior frequency of injection of LA (12). Patients receiving lanreotide LA $(30 \mathrm{mg})$ every 14,10 and 7 days were treated with 60, 90 and $120 \mathrm{mg}$ Autogel every 28 days, respectively. After three monthly injections of Autogel, control of GH and IGF-I levels, and symptoms were found to be equivalent to those obtained with LA. Patients from this study were then enrolled into a subsequent study (13). The dose of Autogel was titrated at baseline according to $\mathrm{GH}$ and IGF-I levels at the end of the previous study. Titration was repeated at 4 and 8 months. In the year that the study covered, control of GH and IGF-I levels, and symptoms were all significantly improved with lanreotide Autogel compared with LA.

However the obvious questions remaining thus far unanswered relate to the relative efficacy of lanreotide
Autogel and octreotide LAR, the clinically equivalent doses of these two products, and the effect of switching from LAR to Autogel. In the present study ten patients with acromegaly were switched at baseline from treatment with octreotide LAR $(20 \mathrm{mg})$ to lanreotide Autogel, which was given every 28 days for 24 weeks, including a dose titration step. Control of $\mathrm{GH}$ and IGF-I levels with Autogel was compared with levels at baseline with LAR. Disease control with Autogel was at least equivalent to that obtained with LAR $(20 \mathrm{mg})$.

This was a group of patients with well-controlled acromegaly: baseline mean serum GH level $3.0 \pm 1.7 \mathrm{mU} / \mathrm{l}$ and IGF-I level $212 \pm 70 \mu \mathrm{g} / \mathrm{l}$, on LAR therapy. Furthermore, at baseline, seven of the ten patients, had a normalised age- and sex-adjusted serum IGF-I level, and nine had a mean serum GH level $<5.0 \mathrm{mU} / \mathrm{l}$, on LAR. Overall mean GH levels for the whole group were similar at study endpoint and baseline. Mean IGF-I levels declined throughout the course of the study and were statistically significantly lower at endpoint compared with baseline.

The proportion of patients achieving a mean serum $\mathrm{GH}$ level $<5.0 \mathrm{mU} / \mathrm{l}$ was used as a marker of disease control as the achievement of a post-treatment $\mathrm{GH}$ level below this limit appears to reduce the overall mortality rate in acromegaly to a level similar to the general population (14). A greater proportion of patients achieved both a GH level of $<5.0 \mathrm{mU} / \mathrm{l}$ and a normalised age-adjusted IGF-I level at study endpoint than at baseline.

The initial rise in GH levels observed at week 8 of the study was not unexpected and is likely to relate to a nadir in somatostatin analogue levels being reached at this time, in much the same way as was observed (and directly measured) previously (12). This relates to serum octreotide levels declining whilst lanreotide concentrations had yet to rise to a steady state. These changes may have lead to the withdrawal of one patient from the study at week 12 due to the return of his symptoms of acromegaly. However the rise in serum GH levels in this patient was not great and did not exceed $10 \mathrm{mU} / \mathrm{l}$ at any time. Serum IGF-I levels in the whole group did not reflect this transient rise in GH concentration. Such discordance between GH and IGF-I levels has been well reported previously (15-17).

It appears that mean serum lanreotide levels did not reach a steady state for the whole group during the course of the study, though in six of the ten patients a steady state was achieved. Whilst it would be logical to assume that this was a result of only three injections of the titrated Autogel dose being given, this may not be the case. Even in the group who remained on $90 \mathrm{mg}$ Autogel for the entire 28 weeks, a steady state may not have been achieved, although the change in mean serum lanreotide levels between weeks 24 and 28 was small. Thus it appears that at least 6 months may be required for steady state to be reached with Autogel treatment in some patients. 
When Autogel dose titration was undertaken at week 16 , seven of the ten patients either remained on the initial $90 \mathrm{mg}$ dose, or received a reduced dose of $60 \mathrm{mg}$. Thus it seems that the majority of patients treated with $20 \mathrm{mg}$ LAR every 4 weeks will be well controlled with lanreotide $90 \mathrm{mg}$ Autogel every 4 weeks. The remaining three patients required an increased dose of $120 \mathrm{mg}$ in order to gain optimal biochemical control. This group, which had higher baseline serum $\mathrm{GH}$ levels, was principally responsible for the rise in mean GH levels at week 8 that was seen for the entire study group.

Serum IGF-I levels fell progressively, irrespective of the titrated Autogel dose, suggesting that the significant reduction in mean serum IGF-I levels in the whole group did not simply occur as a result of upwards titration of the Autogel dose. It could be argued that other factors contributed to the observed decline in IGF-I in this study. These include the effect of prior radiotherapy, or a protracted effect of prior octreotide LAR therapy. The former is unlikely, since the decline in IGF-I was seen in all patients, including the five $(50 \%)$ who had not had prior radiotherapy. IGF-I concentration has been shown to decline progressively with prolonged somatostatin analogue therapy (17). This is also, however, an unlikely explanation for the IGF-I decline in this study, since levels continued to decline to week 28, far beyond the therapeutic effect of octreotide LAR, which was stopped at week 0 .

One aim of this study was to establish whether switching from LAR to Autogel would compromise control of biochemical markers and symptoms of acromegaly. The study was not designed to show relative efficacy in terms of GH/IGF-I control with Autogel compared with LAR. In a study of only ten patients, it is clearly difficult to observe statistically significant differences in markers of disease control. Since this group of patients had well-controlled acromegaly prior to Autogel treatment, the scope for detecting further improvement in biochemical disease control may have been limited.

Lanreotide Autogel was well tolerated in this study with no reported gastrointestinal adverse events. In previous studies gastrointestinal adverse effects were reported with an equal, or reduced frequency with Autogel in comparison with lanreotide LA (12). The lack of gastrointestinal adverse events in the present study may relate to a degree of tolerance in these patients, since they had received longstanding somatostatin analogue therapy. However, taking into account the results from previous studies, the reduced 'burst effect' of Autogel, resulting in lower peak lanreotide levels immediately after injection may also be contributory (12). The local injection site reaction in one patient is consistent with the observations from previous large studies where injection site adverse events were reported to occur with a frequency of $<7 \%$ (12).
In conclusion, switching from octreotide LAR to lanreotide Autogel, with active dose titration, in this small group of patients with well-controlled acromegaly resulted in equal control of serum GH levels and improved control of serum IGF-I levels. Autogel was well tolerated and there are no safety concerns associated with switching from LAR. Although disease control had been achieved using the slow-release microparticle preparation, there may be advantages in the newer aqueous gel preparation, especially in its ease of use and patient acceptability.

\section{References}

1 Lancranjan I, Bruns C, Grass P, Jaquet P, Jervell J, Kendall-Taylor P et al. Sandostatin LAR: a promising therapeutic tool in the management of acromegalic patients. Metabolism 199645 (Suppl 1) $67-71$.

2 Amato G, Mazziotti G, Rotondi M, Lorio S, Doga M, Sorvillo F et al. Long-term effects of lanreotide SR and octreotide LAR on tumour shrinkage and $\mathrm{GH}$ hypersecretion in patients with previously untreated acromegaly. Clinical Endocrinology 200256 65-71.

3 Freda P. Somatostatin analogues in acromegaly. Journal of Clinical Endocrinology and Metabolism 200287 3013-3018.

4 Ferone D, Colao A, Van-de-Lely A \& Lamberts S. Pharmacotherapy or surgery as primary treatment for acromegaly? Drugs and Ageing $20001781-92$.

5 Bevan J, Atkin S, Atkinson A, Bouloux P, Hanna F, Harris P et al. Primary medical therapy for acromegaly: an open, prospective, multi-center study of the effects of subcutaneous and intramuscular slow-release octreotide on growth hormone, insulin-like growth factor-I, and tumor size. Journal of Clinical Endocrinology and Metabolism $2002 \mathbf{8 7} 4554-4563$.

6 Sheppard M, Shapiro B, Pimstone B, Kronheim S, Berelowitz M \& Gregory M. Metabolic clearance and plasma half-disappearance time of exogenous somatostatin in man. Journal of Clinical Endocrinology and Metabolism $1979 \mathbf{4 8} 50-53$.

7 Skamene A \& Patel Y. Infusion of graded concentrations of somatostatin in man: pharmacokinetics and differential inhibitory effects on pituitary and islet hormones. Clinical Endocrinology $198420555-564$.

8 Nicholls J, Wynick D, Domin L, Sandler L \& Bloom S. Pharmacokinetics of the long-acting somatostatin analogue octreotide (SMS 201-995) in acromegaly. Clinical Endocrinology $1990 \quad 32$ 545-550.

9 Kuhn J, Basin C, Mollard M, deRouge B, Baudoin C, Obach R et al. Pharmacokinetic study and effects on growth hormone secretion in healthy volunteers of the new somatostatin analogue BIM 23014. European Journal of Clinical Endocrinology $1993 \mathbf{4 5}$ $73-77$.

10 Heron I, Thomas F, Dero M, Gancel A, Ruiz J, Schatz B et al. Pharmacokinetics and efficacy of a long-acting formulation of the new somatostatin analogue BIM 23014 in patients with acromegaly. Journal of Clinical Endocrinology and Metabolism $1993 \mathbf{7 6}$ $721-727$.

11 Grass P, Marbach P, Bruns C \& Lancranjan I. Sandostatin LAR (microencapsulated octreotide acetate) in acromegaly: pharmacokinetic and pharmacodynamic relationships. Metabolism $1996 \mathbf{4 5}$ (Suppl 1) 27-30.

12 Caron P, Beckers A, Cullen DR, Goth MI, Gutt B, Laurberg P et al. Efficacy of the new long-acting formulation of lanreotide (lanreotide Autogel) in the management of acromegaly. Journal of Clinical Endocrinology and Metabolism 2002 87 99-104.

13 Caron P 2002 One-year treatment with titrated doses of lanreotide Autogel in patients with acromegaly. Proceedings of the Endocrine Society, 84th Annual Meeting, San Francisco, CA, USA. OR13-6. 
14 Orme S, McNally R, Cartwright R \& Belchetz P. Mortality and cancer incidence in acromegaly: a retrospective cohort study. Journal of Clinical Endocrinology and Metabolism $1998832730-2734$.

15 Bates A, Evans A, Jones P \& Clayton R. Assessment of GH status in acromegaly using serum growth hormone, serum insulin-like growth factor-1 and urinary growth hormone secretion. Clinical Endocrinology $1995 \mathbf{4 2} 417-423$.

16 Biermasz NR, van den Oever NC, Frolich M, Arias AM, Smit JW, Romijn JA et al. Sandostatin LAR in acromegaly: 6-week injection interval suppresses $\mathrm{GH}$ secretion as effectively as a 4-week interval. Clinical Endocrinology 200358 288-295.
17 Cozzi R, Attanasio R, Montini M, Pagani G, Lasio G, Lodrini S et al. Four-year treatment with octreotide-long-acting repeatable in 110 acromegalic patients: predictive value of short-term results? Journal of Clinical Endocrinology and Metabolism $2003 \mathbf{8 8}$ 3090-3098.

Received 17 October 2003

Accepted 18 December 2003 